\title{
Polymer-Protected Bimetallic Nanocluster Catalysts Having Core/Shell Structure for Accelerated Electron Transfer in Visible-Light-Induced Hydrogen Generation
}

\author{
Naoki TOSHIMA ${ }^{\dagger}$ and Kazutaka HIRAKAWA* \\ Department of Materials Science and Engineering, \\ Science University of Tokyo in Yamaguchi, Onoda-shi. Yamaguchi 756-0884. Japan. \\ *Department of Applied Chemistry, School of Engineering, \\ The University of Tokyo, Hongo, Bunkyo-ku, Tokyo 113-8656. Japan
}

(Received May 9, 1999)

\begin{abstract}
A visible-light-induced electron transfer system was constructed by using tris(bipyridine)ruthenium(III), methyl viologen, EDTA and colloidal metal nanocluster as photosensitizer, electron relay, sacrificial electron donor and reductive catalyst, respectively. Polymer-protected $\mathrm{Au}, \mathrm{Pt}, \mathrm{Pd}, \mathrm{Rh}$ and $\mathrm{Ru}$ monometallic, and $\mathrm{Au} / \mathrm{Pt}, \mathrm{Au} / \mathrm{Pd}, \mathrm{Au} / \mathrm{Rh}$ and $\mathrm{Pt} / \mathrm{Ru} \mathrm{bimetallic}$ nanocluster catalysts were prepared as colloidal dispersions by alcohol-reduction, and applied to the catalysts for the above reaction. The rate of electron transfer from methyl viologen cation radical to the metal nanocluster catalyst is proportional to the hydrogen generation rate at a steady state. All the electrons accepted by metal nanocluster catalysts are used for the hydrogen generation. Both electron transfer and hydrogen generation rates increase when the colloidal dispersions of bimetallic nanoclusters are used in place of the corresponding monometallic nanoclusters. An Au-core/Rh-shell structure has been suggested by UV-Vis spectrum measurement for Au/Rh bimetallic nanoclusters.
\end{abstract}

KEY WORDS Bimetallic Nanocluster / Colloidal Metal / Catalyst / Visible-Light-Induced Hydrogen Generation / Electron Transfer / Polymer-Protected Metal Cluster / Methyl Viologen /

Conversion of solar photoenergy is a very important theme for human beings. One of the potential methods for solar photoenergy conversion is construction of an artificial photosynthetic system taking after the natural photosynthesis. Various kinds of artificial photosynthetic systems have been proposed so far.' One of the most important and simplest concepts is visible-light-induced decomposition of water to produce oxygen and hydrogen. In order to make this concept realized, an approach is the construction of heterogeneous photocatalytic systems composed of semiconductor such as $\mathrm{TiO}_{2}$, while the other approach is that of homogenious aqueous solutions composed of photosensitizer, electron mediator, and oxidative and reductive catalysts. Colloidal dispersions of noble metals, especially platinum dispersions, are well known as the reductive catalyst in aqueous solutions, producing molecular hydrogen from protons and electrons. Because of transparency for visible light, the colloidal dispersions of platinum are an effective catalyst for the photocatalytic reactions. Many investigations about visible-lightinduced hydrogen generation using colloidal platinum catalysts have been reported. ${ }^{2-6}$

As for the catalytic activity of colloidal metal dispersions much attention has been paid to bimetallic nanoclusters. ${ }^{7.8}$ Some examples have been reported that bimetallic nanoclusters are more active as catalysts than the corresponding monometallic nanoclusters. ${ }^{9-15}$ It is known in practice that the activity and selectivity of metal catalysts can be improved by addition of other components. The effects of added components can often be explained in terms of an ensemble and/or a ligand effect in catalyses. For example, Sinfelt and coworkers have vigorously studied inorganic oxidesupported bimetallic nanoclusters for catalysis and analyzed their microstructures by an EXAES technique. ${ }^{16}$ These supported bimetallic catalysts have been applied to catalyses for hydrogenation of olefins and carbon-skeleton rearrangement of hydrocarbons. The alloy structure can be carefully examined to understand their catalytic properties.

\footnotetext{
To whom correspondence should be addressed.
}

In contrast, colloidal dispersions of bimetallic nanoclusters have not been well-examined until recently. Colloidal dispersions of $\mathrm{Ag} / \mathrm{Au}$ bimetallic nanoclusters were prepared by $\gamma$-irradiation for the study of electrochemical reactions. ${ }^{17}$ Trimetallic nanoclusters were also prepared by the same method and applied to investigation of optical properties. ${ }^{18} \mathrm{Ag} / \mathrm{Pt}$ and $\mathrm{Ag} / \mathrm{Pd}$ bimetallic nanoclusters were obtained by chemical reduction of the corresponding double complexes. ${ }^{19}$ Bönnemann et al. used hydrotriorganoborates as a reductant to get $\mathrm{Pt} / \mathrm{Rh}$ bimetallic nanoclusters, which were supported on charcoals and applied to catalysts for hydrogenation of crotonic acid. ${ }^{20} \mathrm{Cu} / \mathrm{Pd}$ bimetallic nanoclusters were prepared by thermal decomposition of the mixtures of the corresponding metal acetates in the presence or absence of protective polymers, ${ }^{21}$ while the exact $\mathrm{Cu} / \mathrm{Pd}$ bimetallic nanoclusters with 0 -valent $\mathrm{Cu}$ were prepared with a modified polyol process. ${ }^{13,22}$

We have developed a novel method to prepare colloidal dispersions of noble metal nanoclusters by alcohol-reduction of the corresponding metal ions in the presence of watersoluble polymers. ${ }^{23}$ The nanoclusters thus prepared have the following advantages;

1) small in size,

2) narrow in size distribution,

3) stable in water and in an organic solvent as well, and

4) active as the catalyst.

Complexation with the water-soluble polymer like $\operatorname{poly}(N$-vinyl-2-pyrrolidone)(PVP) and polyvinylalcohol is a very important concept during the preparation process of colloidal dispersions of noble metal nanoclusters, as illustrated in Figure 1.

When alcohol-reduction in the presence of PVP is applied to the mixtures of two kinds of noble metal ions, not the mixtures of two kinds of monometallic nanoclusters but bimetallic nanoclusters, each particle of which is composed of two kinds of elements, can be obtained in a series of combinations of two kinds of noble metals, such as $\mathrm{Au} / \mathrm{Pt}$, $\mathrm{Au} / \mathrm{Pd},{ }^{10} \mathrm{Pd} / \mathrm{Pt}{ }^{9}$ and $\mathrm{Pt} / \mathrm{Rh}^{2}{ }^{24}$ The structures of these bimetal- 


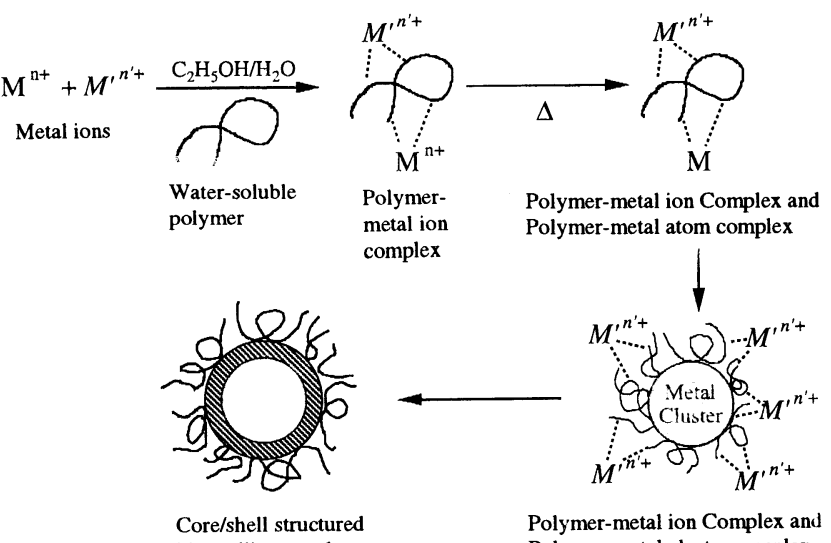

bimetallic nanocluster Polymer-metal cluster complex

Figure 1. The illustration of the preparation process of core/shell structured bimetallic nanoclusters by alcohol-reduction in the presence of water-soluble polymer.

lic nanoclusters were analyzed by an EXAFS technique as well as other analytical methods. Interestingly the so-called core/shell structure has been found to be common for the four couples examined. For example $\mathrm{Pd} / \mathrm{Pt}$ bimetallic nanoclusters have an average diameter of $1.4 \mathrm{~nm}$ corresponding to 55 atoms with a fcc structure. When $\mathrm{Pd} / \mathrm{Pt}$ atomic ratio is $4 / 1$, the exact core/shell structured model can be proposed, where $13 \mathrm{Pt}$ atoms form a core and $42 \mathrm{Pd}$ atoms surround the core to form a shell. ${ }^{9}$ In addition, the bimetallic nanoclusters at $\mathrm{Pd} / \mathrm{Pt}=4$ have the highest catalytic activity for selective partial hydrogenation of 1,3-cyclooctadiene to cyclooctene among the $\mathrm{Pd} / \mathrm{Pt}$ bimetallic nanoclusters with various $\mathrm{Pd} / \mathrm{Pt}$ ratios. The similar trends in structure and catalysis are observed for $\mathrm{Au} / \mathrm{Pd}$ bimetallic nanoclusters as well. ${ }^{10}$

The colloidal dispersions of $\mathrm{Au} / \mathrm{Pt}$ bimetallic nanoclusters were first applied by Harriman to the catalysis for visiblelight-induced hydrogen generation in an aqueous solution. In the report $\mathrm{Au} / \mathrm{Pt}$ bimetallic nanoclusters were prepared by $\gamma$-irradiations. ${ }^{25}$ We have also reported that Au/Pt bimetallic nanoclusters, prepared by alcohol-reduction, have higher catalytic activities for visible-light-induced hydrogen generation than the corresponding monometallic catalysts. ${ }^{11}$

The electron transfer from the electron relay, methyl viologen cation radical, to metal nanocluster catalysts is an essential and very important step to understand the process of visible-light-induced hydrogen generation and to produce a highly active metal nanocluster catalyst for hydrogen generation. The electron transfer from methyl viologen cation radical, prepared by $\gamma$-ray irradiation, to metal colloids were reported by Meisel et al. ${ }^{26,27}$ In their reports the electron transfer occurs with a diffusion control process when metal colloids are just added into the solution of methyl viologen cation radical. However, to our knowledge, the electron transfer rate has not been investigated at a steady state of hydrogen generation.

In the present paper we describe the syntheses of colloidal dispersions of various bimetallic nanoclusters and the electron transfer dynamics at a steady state of hydrogen generation in an aqueous solution of the visible-lightinduced electron transfer system composed of tris(bipyridine)ruthenium(III), methyl viologen, EDTA and metal nanocluster catalyst, as well as catalytic activities of the bimetallic nanoclusters.

\section{EXPERIMENTAL}

\section{Synthesis and Characterization of Colloidal Dispersions of} Metal Nanoclusters

The colloidal dispersions of poly( $N$-viny 1-2-pyrrolidone) (PVP)-protected metal nanoclusters were prepared by an alcohol-reduction method in the same way as previously reported. ${ }^{14}$ Poly $(N$-vinyl-2-pyrrolidone) $(\mathrm{PVP}-\mathrm{K} 30, \mathrm{MW}=$ 40,000, Tokyo Chemical Ind., Ltd., $2.0 \mathrm{mmol}, 40$ times the mole of metal ions in monomeric unit) and metal ions (5.0 $\times$ $10^{-2} \mathrm{mmol}$, final concentration $=1.0 \mathrm{mmol} \mathrm{dm}^{-3}$ ) were mixed in ethanol/water $(1 / 1, \mathrm{v} / \mathrm{v})$ to form a $50 \mathrm{~cm}^{3}$ solution. The mixed solutions were stirred and heated to refluxing at 95 $100^{\circ} \mathrm{C}$ for $2 \mathrm{~h}$, giving colloidal dispersions. Single ions of $\mathrm{Au}, \mathrm{Pt}, \mathrm{Pd}, \mathrm{Rh}$ and $\mathrm{Ru}$, and mixtures (1/1, mole/mole) of pairs of $\mathrm{Au} / \mathrm{Pt}, \mathrm{Au} / \mathrm{Pd}, \mathrm{Au} / \mathrm{Rh}$ and $\mathrm{Pt} / \mathrm{Ru}$ ions were used as metal sources. The following metal salts were used as the metal ion sources; $\mathrm{HAuCl}_{4} \cdot 4 \mathrm{H}_{2} \mathrm{O}$ (Wako Pure Chemical Ind.), $\mathrm{H}_{2} \mathrm{PtCl}_{6} \cdot 6 \mathrm{H}_{2} \mathrm{O}$ (Wako Pure Chemical Ind.), $\mathrm{PdCl}_{2}$ (Nakarai Tesque Ind.), $\mathrm{RhCl}_{3} \cdot 3 \mathrm{H}_{2} \mathrm{O}$ (Wako Pure Chemical Ind.), and $\mathrm{RuCl}_{3} \cdot 3 \mathrm{H}_{2} \mathrm{O}$ (Wako Pure Chemical Ind.).

Transmission electron micrographs (TEM) of the metal nanoclusters were taken by using a Hitachi model H-7000 electron microscope operated at $100 \mathrm{kV}$ of acceleration voltage at magnification of 100,000 . The carbon-supported copper mesh microgrid, kindly supplied by Dr. K. Adachi, was used as a support for metal nanoclusters. The diameter of each particle of metal nanoclusters was measured on the basis of enlarged TEM photographs (magnification 200,000). The histogram of particle size distribution and the average diameter were obtained on the basis of measurements of three hundred particles in an arbitrary chosen area of the photograph.

\section{Visible-Light-Induced Electron Transfer System}

Typical reactions were performed as follows: A $20 \mathrm{~cm}^{3}$ Pyrex Schlenk tube was charged with $10 \mathrm{~cm}^{3}$ of an aqueous solution, containing $1.0 \times 10^{-1} \mathrm{~mol} \mathrm{dm}^{-3}$ of an ethylenediaminetetraacetic acid disodium salt $\left(\mathrm{Na}_{2}\right.$ EDTA, a sacrificial electron donor, Wako Pure Chemicals Ind.), $1.4 \times 10^{-4}$ mol $\mathrm{dm}^{-3}$ of tris(bipyridine)ruthenium(II) dichloride ([Ru (bpy) $\left.{ }_{3}\right] \mathrm{Cl}_{2}$, a photosensitizer, prepared according to the literature $^{28}$ ) and $1.4 \times 10^{-3} \mathrm{~mol} \mathrm{dm}^{-3}$ of 1,1'-dimethyl-4,4'-bipyridium dichloride (methyl viologen, $\mathrm{MVCl}_{2}$, an electron relay, Tokyo Chemical Ind., Ltd.). The colloidal metal dispersions were added at last to obtain the above mixed solution involving metal nanoclusters at designed concentrations. The mixtures were degassed by three times of freeze-thawcycles and then the tubes were filled with 1 atm of nitrogen (purity 99.999\%). The photoirradiation was carried out with an Ushio $500 \mathrm{~W}$ super-high-pressure mercury lamp through a UV cut filter (UV-39, Toshiba Glass Co., $\lambda>390 \mathrm{~nm}$ ) in a water bath maintained at $30^{\circ} \mathrm{C}$. The products in gas phase were analyzed with a Shimadzu model GC-14A GC apparatus using an MS $13 \mathrm{X}$ column at $60^{\circ} \mathrm{C}$.

The solution at the same concentrations of chemicals with or without metal nanoclusters was prepared in a quartz cell to produce a methyl viologen cation radical by irradiation with visible light. Decay of the methyl viologen cation radical was measured with a Shimadzu model UV-3100PC $\mathrm{UV}-\mathrm{Vis}$ photospectrometer to calculate the electron transfer 
rate from the methyl viologen cation radical to metal nanoclusters.

\section{RESULTS AND DISCUSSION}

\section{Synthesis and Characterization of Various Monometallic} and Bimetallic Nanoclusters

Colloidal dispersions of metal nanoclusters were prepared by alcohol reduction from the corresponding metal ions according to the following formulae. ${ }^{14}$

$$
\begin{aligned}
& 2 \mathrm{HAuCl}_{4}+3 \mathrm{C}_{2} \mathrm{H}_{5} \mathrm{OH} \rightarrow \\
& 2 \mathrm{Au}+3 \mathrm{CH}_{3} \mathrm{CHO}+8 \mathrm{HCl}
\end{aligned}
$$

$$
\begin{aligned}
\mathrm{H}_{2} \mathrm{PtCl}_{6}+2 \mathrm{C}_{2} \mathrm{H}_{5} \mathrm{OH} \rightarrow & \\
\mathrm{Pt} & +2 \mathrm{CH}_{3} \mathrm{CHO}+6 \mathrm{HCl}
\end{aligned}
$$

$\mathrm{PdCl}_{2}+\mathrm{C}_{2} \mathrm{H}_{5} \mathrm{OH} \rightarrow \mathrm{Pd}+\mathrm{CH}_{3} \mathrm{CHO}+2 \mathrm{HCl}$

$$
\begin{aligned}
& 2 \mathrm{RhCl}_{3}+3 \mathrm{C}_{2} \mathrm{H}_{5} \mathrm{OH} \rightarrow \\
& 2 \mathrm{Rh}+3 \mathrm{CH}_{3} \mathrm{CHO}+6 \mathrm{HCl}
\end{aligned}
$$

$$
2 \mathrm{RuCl}_{3}+3 \mathrm{C}_{2} \mathrm{H}_{5} \mathrm{OH} \rightarrow
$$

$$
2 \mathrm{Ru}+3 \mathrm{CH}_{3} \mathrm{CHO}+6 \mathrm{HCl}
$$

Bimetallic nanoclusters with Au-core were prepared by co-reduction of $\mathrm{Au}$ and $\mathrm{Pt}$ or Pd ions in ethanol using PVP as a protective agent. In the $\mathrm{Au} / \mathrm{Pt}$ and $\mathrm{Au} / \mathrm{Pd}$ bimetallic nanoclusters, the Au-core/Pt- or Pd-shell structure has been supported by UV-Vis spectra, since the colloidal dispersions of bimetallic nanoclusters with an $\mathrm{Au}$-core/Pt- or Pd-shell structure do not show the specific color based on the surface plasmon absorption of $\mathrm{Au}$ nanoclusters as previously reported. ${ }^{10,11}$ Based on the similar consideration, the $\mathrm{Au} / \mathrm{Rh}$ bi-

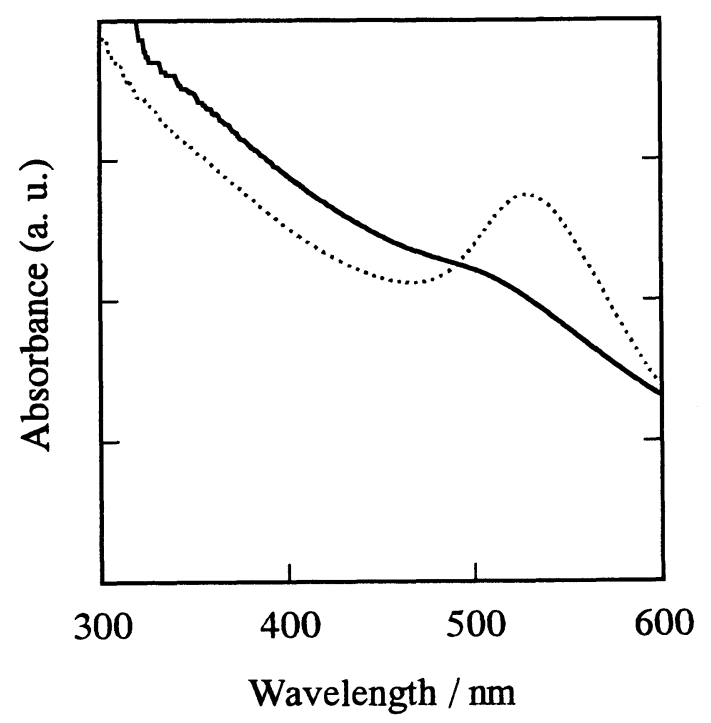

Figure 2. Absorption spectra of the colloidal dispersions of $A u / R h$ (1/1) bimetallic nanoclusters (solid line) and the physical mixture of $\mathrm{Au}$ and Rh monometallic nanoclusters (dotted line).

Table I. Average diameter $(d)$ and standard deviation $(\sigma)$ of monometallic and bimetallic nanoclusters

\begin{tabular}{cccccccccc}
\hline Metal & $\mathrm{Au}$ & $\mathrm{Pt}$ & $\mathrm{Pd}$ & $\mathrm{Rh}$ & $\mathrm{Ru}$ & $\mathrm{Au} / \mathrm{Pt}$ & $\mathrm{Au} / \mathrm{Pd}$ & $\mathrm{Au} / \mathrm{Rh}$ & $\mathrm{Pt} / \mathrm{Ru}$ \\
\hline $\mathrm{d} / \mathrm{nm}$ & 9.2 & 2.3 & 1.9 & 2.2 & 2.2 & 2.1 & 2.4 & 2.6 & 2.0 \\
$\sigma / \mathrm{nm}$ & 4.4 & 1.1 & 0.8 & 1.0 & 1.0 & 1.2 & 1.6 & 1.4 & 0.8 \\
\hline
\end{tabular}

Polym. J., Vol. 31, No. 11-2, 1999 metallic nanoclusters can be proposed to have an Au-core/ $\mathrm{Rh}$-shell structure because the surface plasmon absorption of $\mathrm{Au}$ was rarely observed as shown in Figure 2. The TEM photographs and the particle diameter distribution histograms of $\mathrm{Au} / \mathrm{Rh}$ bimetallic nanoclusters as well as $\mathrm{Pt} / \mathrm{Ru}$ bimetallic ones showed that the metal nanoclusters prepared here have enough small in size and narrow in size distribution. Table I summarizes average particle diameters and standard deviations of $\mathrm{Au}, \mathrm{Pt}, \mathrm{Pd}, \mathrm{Rh}$ and $\mathrm{Ru}$ monometallic, and $\mathrm{Au} / \mathrm{Pt}, \mathrm{Au} / \mathrm{Pd}, \mathrm{Au} / \mathrm{Rh}$ and $\mathrm{Pt} / \mathrm{Ru}$ bimetallic nanoclusters.

\section{Electron Transfer from $\mathrm{MV}^{+}$to Metal Nanoclusters}

PVP-protected monometallic and bimetallic nanoclusters were applied to the catalyst for visible-light-induced hydrogen generation from water in the system composed of EDTA $/ \mathrm{Ru}(\mathrm{bpy})_{3}{ }^{2+} / \mathrm{MV}^{2+} /$ metal nanocluster. The metal nanocluster works as an electron mediator to accept electrons from methyl viologen cation radical and donate them to protons producing hydrogen molecules. Methyl viologen cation radical $\left(\mathrm{MV}^{+\cdot}\right)$ is very stable in the present experimental solution without colloidal dispersions of metal nanoclusters. The decay rate constant of $\mathrm{MV}^{+}$without metal nanoclusters $\left(k_{\mathrm{d}}\right)$ was measured by tracing the fading of blue color of $\mathrm{MV}^{+}$using a conventional spectrophotometer, and determined to be $1.9 \times 10^{-4} \mathrm{~s}^{-1}$ at room temperature. The decay rates of $\mathrm{MV}^{+}$' were accelerated by addition of colloidal dispersions of metal nanoclusters to the solution because of the electron transfer from $\mathrm{MV}^{+}$to metal nanoclusters.

Decay of the absorption spectrum of methyl viologen cation radical at room temperature in the presence of colloidal dispersion of Pt nanoclusters is shown in Figure 3. The decay curve can be expressed by a single exponential way for any kind of metal nanclusters. Thus, when $k_{\mathrm{d}}$ is a decay rate constant of $\mathrm{MV}^{+}$in the absence of metal nanoclusters, $k_{\mathrm{e}}$ is an electron transfer rate constant from $\mathrm{MV}^{+}$to metal nanocluster in the presence of metal nanoclusters, and [Metal] is the concentration of metal nano-

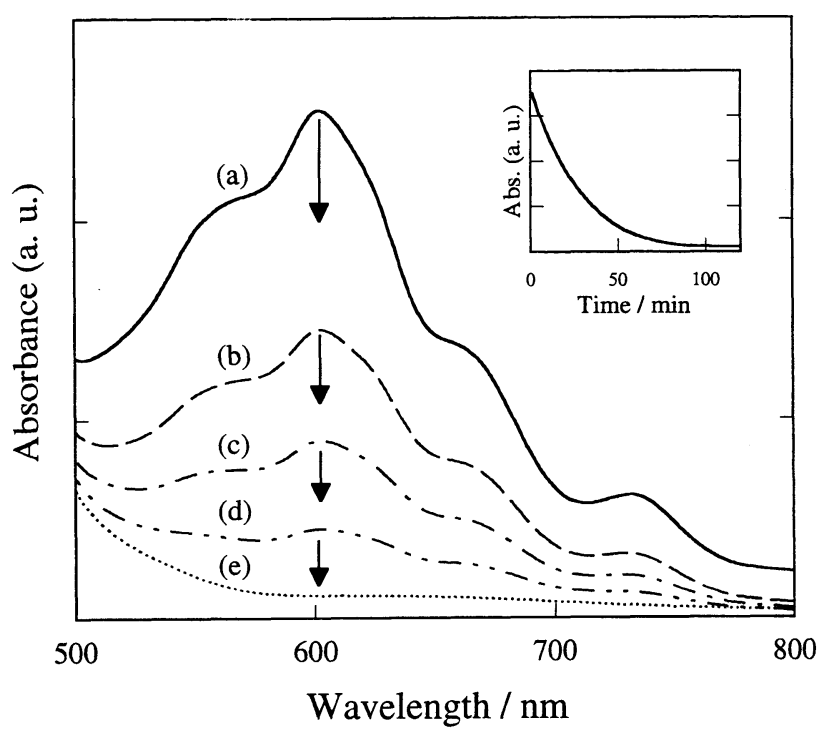

Figure 3. Absorption spectra of methyl viologen cation radical in 0 (a), 20 (b), 40 (c), 60 (d), and 120 min (e) irradiation with visible light in the presence of $\mathrm{Pt}$ nanoclusters. $[\mathrm{Pt}]=2.0 \mu \mathrm{mol} \mathrm{dm}^{-3}$. Inset shows a decay curve of the absorbance at $602.5 \mathrm{~nm}$. 
clusters, then the nanoclusters, then the decay of $\mathrm{MV}^{+}$can be expressed by eqs 6 and 7. Atomic concentration, particle concentration, and total surface area of metal particles can be used for [Metal]. This selection alters the unit of $k_{\mathrm{e}}$.

$$
\begin{aligned}
& -\mathrm{d}\left[\mathrm{MV}^{+\cdot}\right] / \mathrm{d} t=k_{\mathrm{MV}}\left[\mathrm{MV}^{+\cdot}\right] \\
& k_{\mathrm{MV}}=k_{\mathrm{d}}+k_{\mathrm{e}}[\text { Metal }]
\end{aligned}
$$

The relationship between the decay rate and the concentration of $\mathrm{MV}^{+}$, calculated from Figure 3, indicates that the decay rate coefficient of $\mathrm{MV}^{+\cdot} k_{\mathrm{MV}}$ is proportional to the concentration of metal nanoclusters as shown in Figure 4 in the cases of $\mathrm{Pt}$ and $\mathrm{Ru}$ monometallic and $\mathrm{Pt} / \mathrm{Ru}$ bimetallic nanoclusters.

The constant $k_{\mathrm{e}}$ can be calculated from the slopes of Figure 4. The constant $k_{\mathrm{e}}$ was found to depend on the kind of metal. The results are summarized in Table II. The constant $k_{\mathrm{e}}$ of the bimetallic nanocluster is always larger than those of the corresponding monometallic nanoclusters, revealing that the bimetallic nanocluster can accept electrons more easily than the monometallic one. Among the bimetallic nanoclusters examined here the $\mathrm{Pt} / \mathrm{Ru}$ bimetallic nanocluster can accept electrons most easily. However, if the electron transfer rate coefficients are compared per unit surface, which can

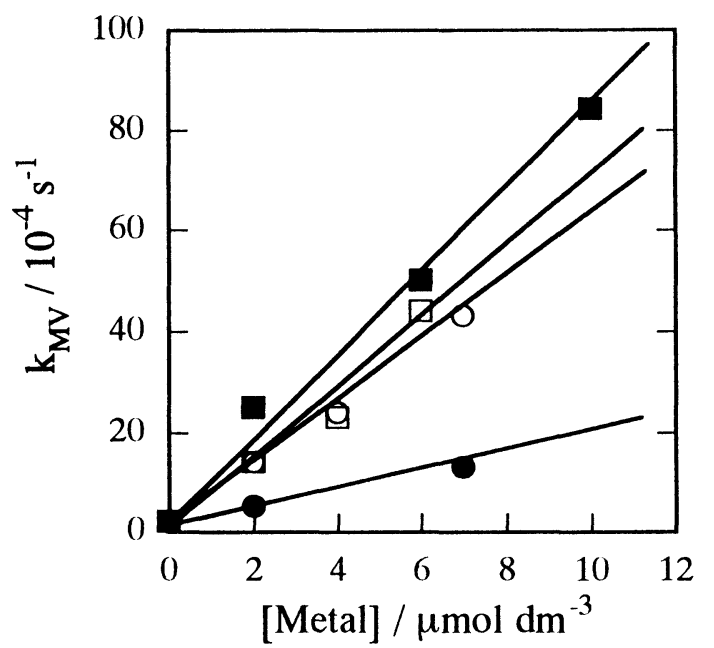

Figure 4. Decay rate coefficients of $\mathrm{MV}^{+}\left(k_{\mathrm{MV}}\right)$ vs. [Metal] in the presence of $\mathrm{Pt}(\bigcirc)$ and $\mathrm{Ru}(\bigcirc)$ monometallic nanoclusters, physical mixture of Pt and Ru monometallic nanoclusters $(\square)$, and Pt/Ru bimetallic nanoclusters ( $\square$ ). Mole ratios of two elements in the bimetallic systems are always $1 / 1$.

Table II. Electron transfer rate coefficients $\left(k_{\mathrm{e}}\right)$ and hydrogen

\begin{tabular}{|c|c|c|c|c|}
\hline $\begin{array}{l}\text { Metal } \\
\text { nanocluster }\end{array}$ & $\begin{array}{c}k_{\mathrm{e}} \\
\mathrm{mol}^{-1} \mathrm{dm}^{3} \mathrm{~s}^{-1} \\
\end{array}$ & $\begin{array}{c}k_{\mathrm{e}(\text { surface })}{ }^{\mathrm{a}} \\
10^{-3} \mathrm{~m}^{-2} \mathrm{dm}^{3} \mathrm{~s}^{-1} \\
\end{array}$ & $\begin{array}{r}k_{\mathrm{H} 2} \\
\mathrm{~s}^{-1} \\
\end{array}$ & $\begin{array}{r}k_{\mathrm{H} 2 \text { (surface) }}{ }^{\mathrm{a}} \\
10^{-6} \mathrm{~mol} \mathrm{~m}^{-2} \mathrm{~s}^{-1} \\
\end{array}$ \\
\hline $\mathrm{Au}$ & 20 & 6.1 & 0.02 & 6.1 \\
\hline $\mathrm{Pt}$ & 160 & 13 & 0.15 & 12 \\
\hline $\mathrm{Pd}$ & 140 & 11 & 0.10 & 7.1 \\
\hline $\mathrm{Rh}$ & 650 & 59 & 0.53 & 48 \\
\hline $\mathrm{Ru}$ & 580 & 48 & 0.45 & 41 \\
\hline $\mathrm{Au} / \mathrm{Pt}$ & 310 & 22 & 0.27 & 19 \\
\hline $\mathrm{Au} / \mathrm{Pd}$ & 220 & 18 & 0.23 & 19 \\
\hline $\mathrm{Au} / \mathrm{Rh}$ & 800 & 73 & 0.58 & 53 \\
\hline $\mathrm{Pt} / \mathrm{Ru}$ & 830 & 63 & 0.80 & 60 \\
\hline
\end{tabular}
generation rate coefficients $\left(k_{\mathrm{H} 2}\right)$

${ }^{\mathrm{a}}$ Rate coefficient per unit surface. be calculated based on the average diameters, then $\mathrm{Au} / \mathrm{Rh}$ bimetallic cluster is the most active.

\section{Visible-Light-Induced Hydrogen Generation}

Reductive production of hydrogen was detected by GC (TCD) on irradiation with visible light in the electron relay system of EDTA / Ru(bpy) ${ }_{3}{ }^{2+} / \mathrm{MV}^{2+} /$ metal nanocluster. In a steady state of the reaction, hydrogen generation increased linearly in proportion to irradiation time of visible light. A typical example of hydrogen generation curve is shown in Figure 5. Total amount of hydrogen generation converges to the limitation, probably because of degradation of methyl viologen by reduction. ${ }^{29}$ Hydrogen generation rates $\left(r_{\mathrm{H} 2}\right)$, measured from the slope of hydrogen generation curve in Figure 5, are in proportion to metal concentration. An example is shown in Figure 6. This is the same tendency as the decay rate coefficients of methyl viologen cation radical. Hydrogen generation rate $\left(r_{\mathrm{H}_{2}}\right)$ can be expressed by eq 8 by using the hydrogen generation rate coefficients $\left(k_{\mathrm{H}_{2}}\right)$.

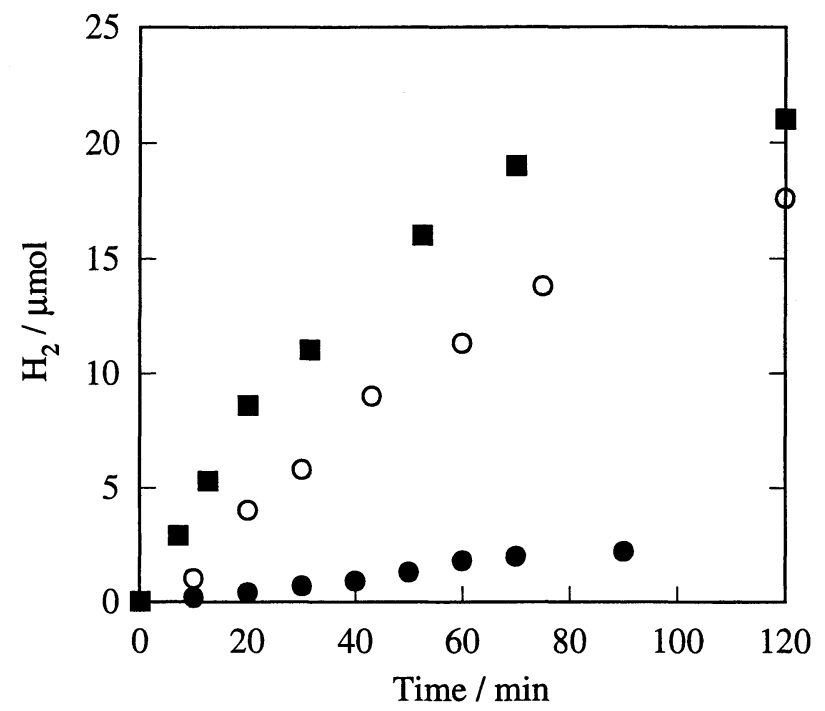

Figure 5. The typical hydrogen generation curve catalyzed by $\mathrm{Au}(\mathrm{O})$ $\mathrm{Pt}(\mathrm{O})$, and $\mathrm{Au} / \mathrm{Pt}(\square)$ nanoclusters. [Metal] $=2.0 \mu \mathrm{mol} \mathrm{dm}{ }^{-3}$.

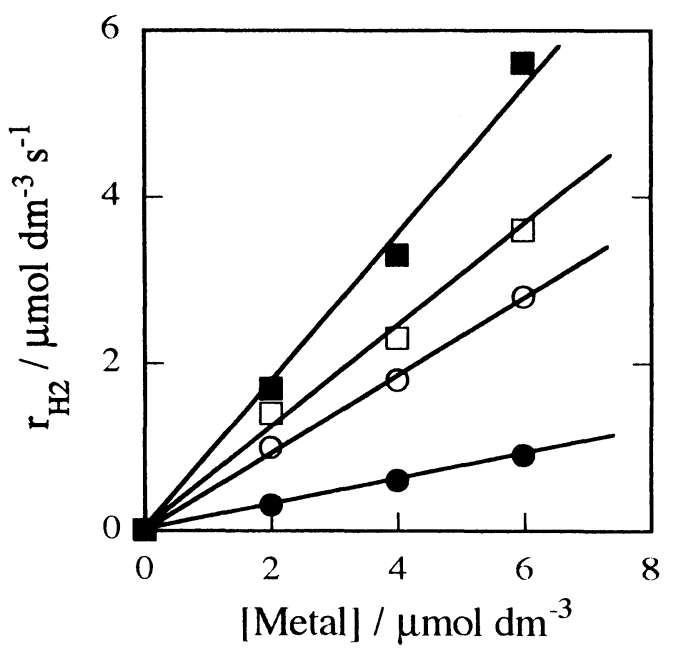

Figure 6. Hydrogen generation rate $\left(r_{\mathrm{H} 2}\right) v s$. [Metal] in the presence of $\mathrm{Pt}(\mathrm{O})$ and $\mathrm{Ru}(\bigcirc)$ monometallic nanoclusters, physical mixture of $\mathrm{Pt}$ and $\mathrm{Ru}$ monometallic nanocluster $(\square)$, and $\mathrm{Pt} / \mathrm{Ru}$ bimetallic nanoclusters ( ). Mole ratios of two elements in the bimetallic systems are always $1 / 1$. 


$$
r_{\mathrm{H} 2}=k_{\mathrm{H} 2}[\text { Metal }]
$$

The results of $k_{\mathrm{H} 2}$ and $k_{\mathrm{H} 2 \text { (surface) }}$ are also summarized in Table II. Again, the hydrogen generation rate coefficient $k_{\mathrm{H} 2}$ for the bimetallic nanocluster is always larger than those of the corresponding monometallic ones. Figure 7 shows the plots of $k_{\mathrm{c}} v s . k_{\mathrm{H} 2}$ obtained by all the results of the present experiments. The linear relationship is clearly demonstrated between $k_{\mathrm{e}}$ and $k_{\mathrm{H} 2}$. This result shows that the efficiency of hydrogen generation, attributed to the electrons accepted from methyl viologen cation radicals, is independent of the kind of the element constructing colloidal metal nanocluster catalysts.

\section{The Relationship between Electron Accepting Ability and Proton Reduction}

The electron transfer rate from methyl viologen cation radical to colloidal metal particles was often thought to proceed by diffusion control. However, this is not always true. Actually we can observe that the rate is in the order of minute by measurement of the decay rate of methyl viologen cation radical in the presence of colloidal dispersions of metal nanoclusters. This rate is much slower than the diffusion control rate. On the other hand, methyl viologen cation radical can be produced at the rate of diffusion of photosensitizer. Because the productive rate of methyl viologen cation radical is very fast, the electron transfer from methyl viologen cation radical to metal nanocluster is a ratedetermining step. There are two possible mechanisms to make the electron transfer as a rate-determining step:

1) The electron transfer from methyl viologen cation radical to metal nanocluster controls the hydrogen generation, since the electron in metal nanoclusters can be transferred to protons to produce hydrogen.

2) Hydrogen generation controls the electron acception of metal nanocluster from methyl viologen cation radical, since the hydrogen generation can consume the electron in metal nanoclusters. In other words, the electron removal from metal nanoclusters by hydrogen generation brings about the next electron acception from methyl viologen cation radical.

If the hydrogen generation rate controls the electron accepting rate of metal nanoclusters, the electron transfer rate coefficient must increase with time after the generation of methyl viologen cation radical ceases. However, the methyl viologen cation radical decays in an exponential way. The decay rate coefficient is constant and independent of time. This phenomenon shows that the first process is possibly the rate determining step. In addition, the hydrogen generation rate coefficient is in proportion to the electron transfer rate coefficient at a steady state. These results mean the electron transfer process from methyl viologen cation radical to metal nanoclusters controls the hydrogen generation rate.

\section{Efficiency of Hydrogen Generation for Electrons Accepted by Metal Nanoclusters}

The linear relationship, observed between the electron transfer rate coefficients and the hydrogen generation rate coefficient, is shown in Figure 7. This linear relationship means that the electrons, which metal nanoclusters accept from methyl viologen cation radicals, can be consumed for the hydrogen generation at a constant efficiency. This efficiency is independent of the kind of metal of nanoclusters.
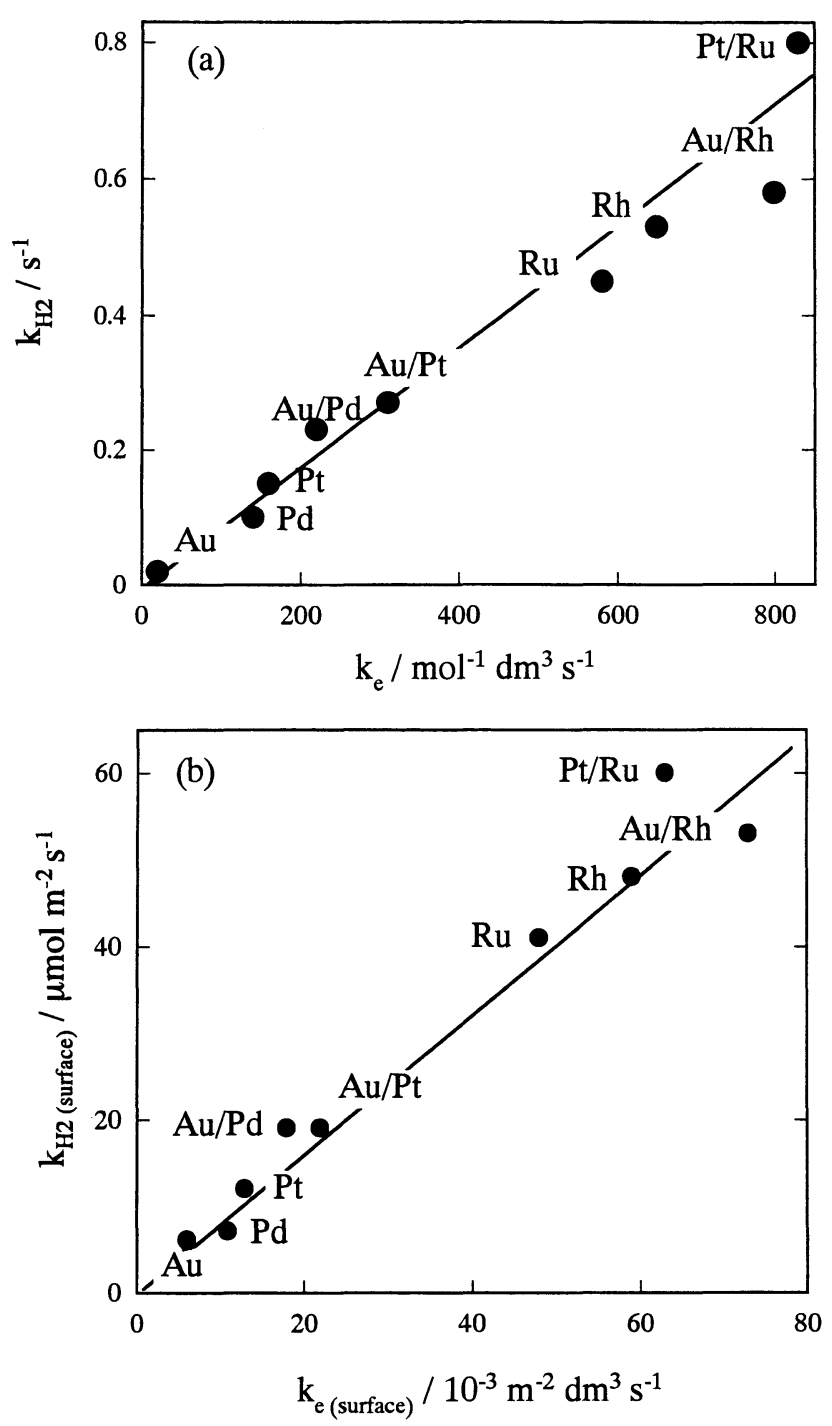

Figure 7. Hydrogen generation rate coefficients $\left(k_{\mathrm{H} 2}\right)$ vs. electron transfer rate coefficients $\left(k_{\mathrm{e}}\right)$. Rates are calculated from atomic concentration of metal (a) and surface area of metal nanoclusters (b).

The efficiency $f$ can be expressed by the following eq 9 .

$$
k_{\mathrm{H} 2}=0.5 f \cdot c\left[\mathrm{MV}^{+\cdot}\right]_{\mathrm{s} 1} k_{\mathrm{e}},
$$

where $f$ is the efficiency of hydrogen generation from the electrons accepted by metal nanocluster from methyl viologen cation radical, $c$ is a factor representing the effect of stirring of the reaction mixtures, and $\left[\mathrm{MV}^{+}\right]_{\mathrm{st}}$ is the concentration of methyl viologen cation radical at a steady state. The efficiancy $f$ can be calculated from the slope of the linear relationship between $k_{\mathrm{e}}$ and $k_{\mathrm{H} 2}$, which can be obtained from the experiments. The slope of Figure $7(0.5 f$. $c\left[\mathrm{MV}^{+\cdot}\right]_{\mathrm{st}}$ in eq 9) is $7.8 \times 10^{-4} \mathrm{~mol} \mathrm{dm}^{-3}$, in which $\left[\mathrm{MV}^{+\cdot}\right]_{\mathrm{st}}$ is calculated to be $2.7 \times 10^{-4} \mathrm{~mol} \mathrm{dm}^{-3}$ by using the measured absorbance and reported molar extinction constant ( $\varepsilon=$ $11,000)^{30}$. The factor $c$ was obtained as 6 by the dependencies of hydrogen generation rate on the stirring, i.e., the plot of hydrogen generation rates with $\left(r_{\mathrm{H} 2}\right)$ and without $\left(r_{\mathrm{H} 2,0}\right)$ stirring (Figure 8). From these values the efficiency $f$ was calculated to be about $100 \%$. This means that all the electrons accepted by metal nanoclusters from methyl viologen cation radical are used for hydrogen generation. 


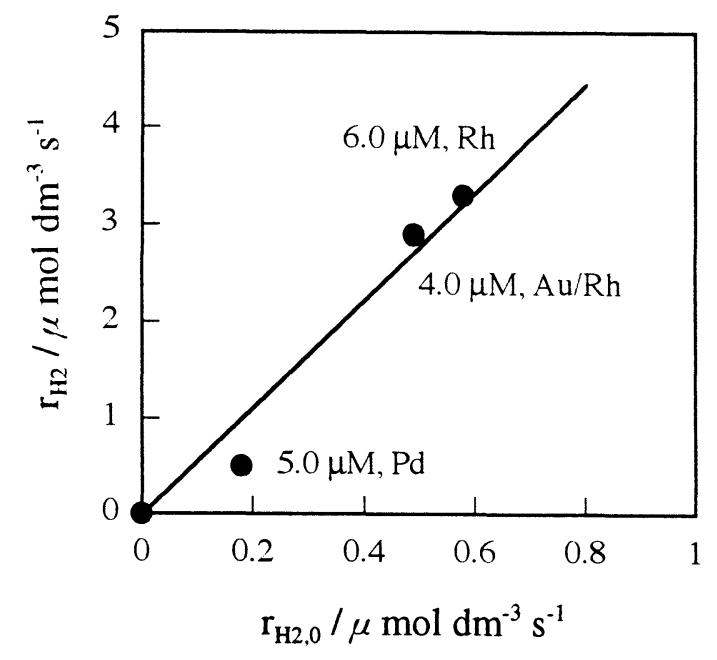

Figure 8. Effect of stirring on the hydrogen generation rate.

\section{CONCLUSION}

Various kinds of colloidal dispersions of monometallic and bimetallic nanoclusters were prepared by alcohol reduction of noble metal ions in the presence of poly $(\mathrm{N}$-vinyl-2pyrrolidone). They are well monodispersed (relatively uniform in size) and stable for months. The Au-containing bimetallic nanoclusters have a core/shell structure, which is confirmed by UV-Vis spectra. Both monometallic and bimetallic nanoclusters work as catalysts for visible-lightinduced hydrogen generation from water in the system of EDTA / $\left[\mathrm{Ru}(\mathrm{bpy})_{3}\right]^{2+} / \mathrm{MV}^{2+} /$ metal nanocluster. The bimetallic nanoclusters are generally more active than the corresponding monometallic nanoclusters. The highest catalytic activity is observed for $\mathrm{Au} / \mathrm{Rh}$ and/or $\mathrm{Pt} / \mathrm{Ru}$ bimetallic nanoclusters among the metal nanoclusters examined here. The hydrogen generation rate coefficients are in proportion to the electron transfer rate coefficient from methyl viologen cation radical to metal nanoclusters at a steady state. The efficiency of hydrogen generation for electrons accepted by metal nanoclusters is independent of the kind of metal nanoclusters and can be calculated to be $c a$. $100 \%$. That is all the electrons accepted by metal nanoclusters from methyl viologen cation radicals are used for hydrogen generation.

Acknowledgment. This work was supported by a Grantin-Aid from Scientific Research on Priority Areas, "New Polymers and Their Nano-Organized Systems" (No. 277/082 46101 ) from the Ministry of Education, Science, Sports and
Culture, Japan.

\section{REFERENCE}

1. M. Kaneko, Ed., “Hikari Kagaku Enerugi Henkan”, IPC, Tokyo (1997).

2. J. Kiwi and M. Grätzel, Nature, 281, 657 (1979).

3. J. Kiwi and M. Grätzel, J. Am. Chem. Soc., 101, 7214 (1979).

4. P. A. Brugger, P. Cuendet, and M. Grätzel, J. Am. Chem. Soc., 103, 2923 (1981).

5. A. J. Frank and K. L. Stevenson, J. Chem., Soc., Chem. Commun., 593 (1981).

6. N. Toshima, M. Kuriyama, Y. Yamada, and H. Hirai, Chem. Lett., 793 (1981).

7. N. Toshima and T. Yonezawa, New J. Chem., 22, 1179 (1998).

8. N. Toshima, J. Macromol. Sci.-Chem., A27, 1225 (1990).

9. N. Toshima, M. Harada, T. Yonezawa, K. Kushihashi, and K. Asakura, J. Phys. Chem., 95, 7448 (1991).

10. N. Toshima, M. Harada, Y. Yamazaki, and K. Asakura, J. Phys. Chem., 96, 9927 (1992).

11. T. Yonezawa and N. Toshima, J. Mol. Catal., 83, 167 (1993).

12. T. Yonezawa and N. Toshima, J. Chem. Soc. Faraday Trans., 91, 4111 (1994).

13. N. Toshima and Y. Wang, Adv. Mater., 6, 245 (1994).

14. N. Toshima, Y. Yamaji, T. Teranishi, and T. Yonezawa, Z. Naturforsch., 50A, 283 (1995).

15. A. F. Lee, C. J. Baddeley, C. Hardacre, R. M. Ormerod, R. M. Lambert, G. Schmid, and H. West, J. Phys. Chem., 99, 6096 (1995).

16. J. H. Sinfelt, Acc. Chem. Res., 20, 134 (1987).

17. P. Mulvaney, M. Giersig, and A. Henglein, J. Phys. Chem., 97, 7061 (1993)

18. P. Mulvaney, M. Giersig, and A. Henglein, J. Phys. Chem., 96, 10419 (1992).

19. K. Torigoe, Y. Nakajima, and K. Esumi, J. Phys. Chem., 97, 8304 (1993); K. Torigoe and K. Esumi, Langmuir, 9, 1664 (1993).

20. H. Bönnemann, W. Brijoux, R. Brinkmann, R. Fretzen, J. Joussen, R. Köppler, B. Korall, P. Neiteler, and J. Richten, J. Mol. Catal., 86, 129 (1994)

21. K. Esumi, T. Tano. K. Torigoe, and K. Meguro, Chem. Mater., 2 , 564 (1990); J. S. Bradley, E. W. Hill, C. Klein, B. Chaudret, and A. Duteil, Chem. Mater., 5, 254 (1993).

22. N. Toshima and Y. Wang, Chem. Lett., 1611 (1993); N. Toshima and Y. Wang, Langmuir, 10, 4574 (1994).

23. H. Hirai, Y. Nakao, and N. Toshima, J. Macromol. Sci.-Chem. A13, 727 (1979).

24. M. Harada, K. Asakura, and N. Toshima, J. Phys. Chem., 98, 2653 (1994).

25. A. Harriman, J. Chem. Soc., Chem. Commun., 24 (1990).

26. D. Meisel, W. A. Mulac, and M. S. Matheson, J. Phys. Chem., 85, 179 (1981).

27. M. S. Matheson, P. C. Lee, D. Meisel, and E. Pellzzetti, J. Phys Chem., 87, 394 (1983).

28. R. A. Palmer and T. S. Piper, Inog. Chem., 5, 864 (1966).

29. P. Keller, A. Moradpour, E. Amouyal, and H. Kagan, J. Mol. Catal., 7, 539 (1980).

30. T. W. Ebbesen and G. Ferraudi, J. Phys. Chem., 87, 3717 (1983). 